\section{The Aspiration of Stomach Contents During Anaesthesia}

Three articles recently published ${ }^{1,2,3}$ have drawn attention to the grave dangers resulting from aspiration of gastric contents during anaesthesia. Proof of such aspiration was obtained in 16 per cent. of 300 cases, ${ }^{3}$, so that it is by no means a rare accident. It may follow frank vomiting, which is usually obvious and audible to the anaesthetist, but as frequently it results from silent regurgitation which may not be noticed until the mask is removed from the patient's face at the end of the operation. Certain positions predispose to it, especially the lateral and the Trendelenburg. Several techniques favour it, especially deep general anaesthesia and muscle relaxants which render the oesophageal sphincters atonic. It is especially common during operations in which the stomach is handled, and in all those conditions which contribute to delayed emptying or abnormal filling from below the stomach or oesophagus. Emotional states such as pain, anxiety and fear, and grave illness are all causes of delayed emptying. It is dangerously common in labour $^{2}$ and is one of the chief reasons why regional methods of analgesia should be used whenever possible in obstetric cases who are not properly prepared for operation.

Aspiration may take place under anaesthesia during induction, maintenance or recovery. If all patients were returned to bed in the semiprone tonsil position and so left until conscious, the danger during recovery would be materially reduced.

A gastric tube if properly placed and used will reduce the incidence of aspiration, but it must be emphasized that a Ryle's tube can only drain thin fluid, so that an oesophageal tube slightly fatter than a lead pencil should be gently but firmly coaxed into every patient in whom there is a suspicion that the stomach may not be empty. It $:-$ should be left in position until the larynx can be protected either by the insertion and inflation of a? cuffed endotracheal tube, or by the return of the $\frac{0}{\circ}$ cough reflex.

If food is known to be present no general $\frac{\text { ? }}{\sigma}$ anaesthetic must be given until five hours have $\propto$ elapsed, while in all acute abdominal conditions, including intestinal obstruction, strangulated $\overrightarrow{0}$ hernia, peritonitis from any cause, burst abdomenand in most cases of accident requiring deep $\vec{\omega}$ anaesthesia, the stomach should be assumed to beo full. An oesophageal tube should therefore be in $-\frac{0}{3}$ serted before induction of anaesthesia. Asi. Morton and $\mathrm{Wylie}^{\mathrm{1}}$ point out, cases of acute appendicitis do not usually vomit or regurgitate $\tilde{N}^{\omega}$ during anaesthesia.

Aspiration of stomach contents into the lungs can cause respiratory obstruction and death fromo asphyxia or from laryngeal spasm. It can, especially if much gastric acid is aspirated, cause inc two or three hours a syndrome ${ }^{4}$ characterized by bronchospasm, fever and cough simulating acute pulmonary oedema, which may not clear up corb-ci pletely for two or three weeks, with radiological ${ }^{\mathrm{N}}$ appearances of patchy basal congestion. Finale; aspiration bronchopneumonia may follow, and thes patient then runs the risk of sequelae such as atelectasis, pneumonitis, bronchiectasis or lung\% abscess. The right lung, especially the apical areå요 of its lower lobe is soiled more frequently than the $\overrightarrow{\vec{B}}$ left lung because of the anatomical arrangement of 3 the bronchi.

All those orderlies, nurses, residents, surgeons: and anaesthetists, therefore, who are concerned in the management of surgical patients must become 3 . more aspiration conscious, and that which cannoto be accomplished by intelligent prevention must be guarded against by constant watchfulness.

J.A.L.

\title{
REFERENCES
}

I. MORTON, H. J. V., and WYLIE, W. D. (1951), Anaesthesia, 6, 4 . October.

2. MERRILL, R. B., and HINGSON, R.A. (195I), Anaesthesia and Analgesia, 30, 3. May-June.

3. CULVER, G. A., MAKEL, H. P., and BEECHER, H. K. (1951), Annals of Surgery, 133. March.

4. MENDELSON, E. L. (1946), Am. F. Obst. and Gynaecol., 52. Aug. 